\title{
EXPERIMENTAL STUDY ON THE PERFORMANCE OF FRP TENDON ANCHORING DEVICES IN AXIAL TENSION
}

\author{
${ }^{1}$ Ivan V. ABRAMOV, ${ }^{2}$ Pavel V. LEKOMTSEV, ${ }^{3}$ Alexander V. ROMANOV \\ ${ }^{4}$ Andrey V. BUCHKIN, ${ }^{5}$ Zarina S. SAIDOVA, ${ }^{6}$ Zoltan ORBAN ${ }^{*}$ \\ 1,2,3,5 Kalashnikov Izhevsk State Technical University, Studencheskaya St. 7, 426069 \\ Izhevsk, Russia, e-mail: ${ }^{1} \mathrm{~ms} @$ istu.ru, ${ }_{5}^{2}$ lekomtsev@istu.ru, ${ }^{3} \mathrm{~ms}$ istu@mail.ru \\ 5 zarinasaidova@mail.ru \\ ${ }^{4}$ Joint-Stock Company, Research Center of Construction, A. A. Gvozdev NIIZHB \\ 2nd Institutskaya St. 5, 109428 Moscow, Russia, e-mail: ${ }^{4}$ andibuch@inbox.ru \\ ${ }^{6}$ Structural Diagnostics and Analysis Research Group, Faculty of Engineering and Information \\ Technology, University of Pécs, 7624 Boszorkany u. 2, Pécs, Hungary \\ e-mail: 6 orbanz@pmmik.pte.hu
}

Received 30 December 2019; accepted 24 April 2020

\begin{abstract}
The paper presents an experimental research on anchoring devices developed for the pre-tensioning of fiber reinforced polymer tendons in the stress range between 40 and $70 \%$ of tensile strength. The technique of testing, the criteria of assessing the load capacity and the influence of preloading applied on the anchor wedges on the initial tendons slippage are described. The optimal technical configurations of the anchoring device have been obtained, including parameters regarding the necessary prior anchorage of the tendon ends based on the strength properties of the tendon bar and the requirements to avoid slippage during the tensile tests.
\end{abstract}

Keywords: Fiber reinforced polymers, Anchoring systems, Contact pressure, Prestressing, Tension, Wedge anchor

\section{Introduction}

A variety of existing technical solutions for the pre-tensioning of composite Fiber Reinforced Polymer (FRP) tendons [1]-[15] shows that the problem of increasing the reliability of gripping and anchoring devices is of growing importance nowadays.

The most effective way to fix the tendon bar in the test sample is to place it send in the steel sleeve [2], tube [16] or tip [3] and polymerize it with an adhesive or glass-filled epoxy resin. This process provides appropriate conditions for minimal initial deformations in the area of the reinforcing tendon fixation, and results in maximum

\footnotetext{
${ }^{*}$ Corresponding Author
} 
contact area and adhesion ratio. It is proposed in [17] to pour the gripping mechanism in a liquid form through a hole into the mould that contains the previously installed reinforcing rebar, and then press it with clamping elements. Paper [18] presents the results of experiments where fiberglass rods glued into the gripping parts were subjected to uniaxial tension. The author noted that $50 \%$ of the samples under tension have been damaged in the gripping part due to the breakdown of the adhesive layer between the sample and the steel sleeve, and the remaining 50\% failed in the working part and were considered appraisable for defining the tensile strength. Paper [19] gives the results of tensile strength tests of several types of FRP rebars, carried out according to the Russian national standard [16]. In this test the following specimen failure pattern were noted: for small diameters (up to $5 \mathrm{~mm}$ ), the rabar failed at its connection with the anchor device. It was concluded that the proper use of an adhesive substance would require further studies especially on the strength and adhesive properties in the solid state, as well as on the precise centering of the FRP rebars in the sleeves before the polymerization process [20].

Modern systems of steel reinforcement prestressing use collet clamps [21], which have to be constructively adapted for tensioning FRP rebars. This is primarily due to the different physico-mechanical properties (mainly of the working surface hardness) of the steel collet and FRP, low crack resistance of the polymer composite matrix material, relatively low shear strength of FRP due to the absence of reinforcement in the transverse direction.

The above-mentioned factors add up to the formation of surface microcracks in the contact zone and the destruction of the polymer composite matrix material and longitudinal fibers, including the point where reinforcement bar exits from the collet [22], [23], [24]. It is possible to solve this problem by either preventing the direct contact between the steel collet and the rod by using an intermediate sleeve [10], [25], or producing the collet using materials with physic-mechanical properties close to the FRP [1], [4]-[9], [13].

Article [26] shows that an increase in the load capacity of the tension system with an intermediate sleeve can be achieved by subjecting the inner surface of the sleeve to sandblasting, thus improving its frictional properties. The experiment confirmed that the friction coefficient and contact pressure are the main parameters affecting the strength of the cylinder-rod connection.

The second way to eliminate the stress concentration in the rod when using a collet clamp is to make the collet from a softer material. For example, a comparison of the experimental results on uniaxial tension using conventional collet grips of a tensile machine and plastic wedges adapted for testing FPR [27] showed a difference in ultimate tensile capacity. It determined the limiting characteristics of $30 \%$ associated with the destruction of a rebar in the area of steel collet.

Article [28] describes a condition for keeping the rod in the collet clamp under tension: the contact pressure should be lower at the loaded end of the rod and higher at the free end. This can be achieved by using collets of various stiffness along the length [5], [6], [7], [13], or using design features [12], that enable redistribution of contact pressures in the process of rebar tensioning. One of the design features is the angle of inclination of the cone collet and the body angle in the sleeve. It should be pointed out that recommendations of Russian [4], [29] and foreign authors [10], [12] differ. 
Considering the information, mentioned above, the design of the tension device for FRP reinforcement is important, and requires not only the study of issues related to the theoretical justification of the design parameters of the device, but also the technology of manufacturing, subsequent experimental studies and recommendations for using this tension system for prestressing process of concrete structures.

\section{Description of the test method for anchoring devices}

Three series of tests of devices for tensioning of glass-composite reinforcement Glass Fiber Reinforced Polymer (GFRP) were carried out. Reinforcing rods had a diameter of $8 \mathrm{~mm}$, a length of $520 \mathrm{~mm}$, and three different surface treatments:

- set 1 , - the surface treatment is formed by winding the continuous fiber on the power rod;

- set 2, - the surface treatment is formed by pressing out threads of homogeneous material in the FRP rod;

- set 3, - an surface treatment is formed by application of sand coating.

The appearance of the investigated samples of the GFRP rebars is presented in Fig. 1. The geometric and mechanical characteristics that were obtained from previously performed tests to comply with the requirements of GOST 31938 - 2012 [16] are shown in Table I for GFRP rebars produced by different manufacturers.

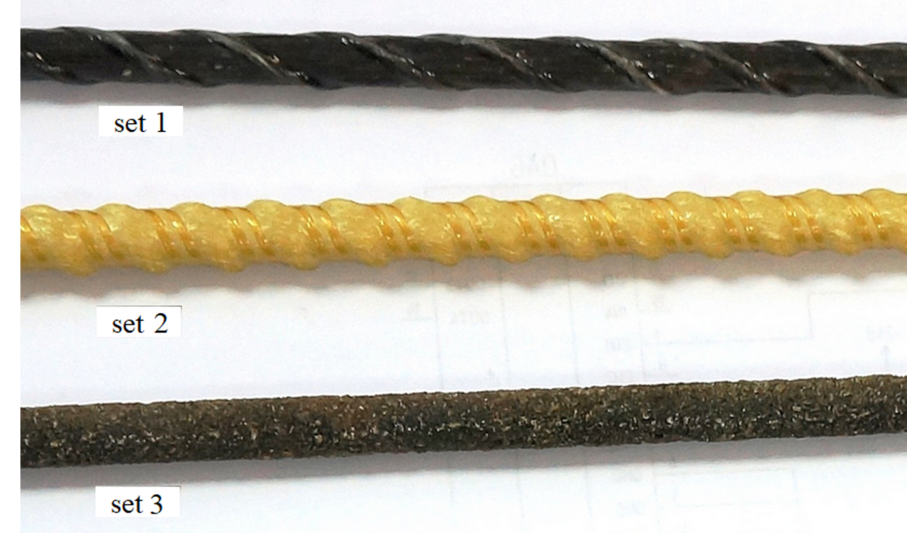

Fig. 1. FRP rods appearance

Before testing, the ends of the reinforcement tendon were fixed by initial pressing of anchor wedges with F1 and F2 forces in mandrels №1 and №2 respectively (see Fig. 2), and then testing beacons (Fig. 3) were glued to the rod close to the ends of the cylinders for the determination of slippage.

Next, the cylinder with a reinforcing rod is fastened in the gripping devices of the testing machine Instron 5982. The testing configuration is presented in Fig. 3. The 
tension force $F p$ was set from 0.4 to 0.7 of the ultimate load at axial tension $F_{u l t}$, the speed of the plate movement was set to $10 \mathrm{~mm} / \mathrm{min}$.

\section{Table I}

Geometric and mechanical characteristics of the tested GFRP rebars

\begin{tabular}{|l|l|l|l|}
\hline \multirow{2}{*}{ Name of the indicator } & \multicolumn{3}{|l|}{ Sample Set Number } \\
\cline { 2 - 4 } & 1 & 2 & 3 \\
\hline Nominal diameter $d_{n}, \mathrm{~mm}$ & 8.33 & 8.30 & 8.35 \\
Tensile strength $\sigma_{u}, \mathrm{MPa}$ & 1291 & 1127 & 1194 \\
Ultimate load at axial tension $\boldsymbol{F}, \mathrm{kN}$ & 70.32 & 60.95 & 65.35 \\
Modulus of elasticity $E_{f}, \mathrm{GPa}$ & 57 & 47 & 50 \\
Relative elongation $\varepsilon_{u}$ up to failure. \% & 2.3 & 2.4 & 2.4 \\
\hline
\end{tabular}

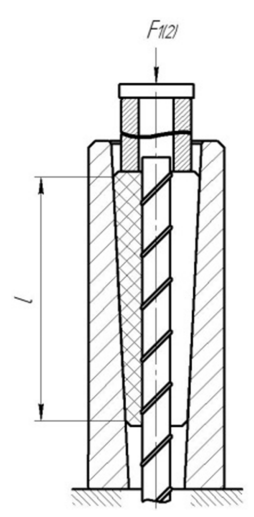

a)

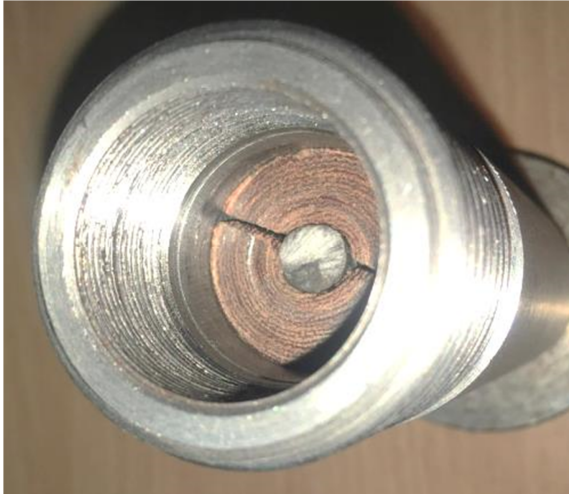

b)

Fig. 2. Preliminary fixation of FRP rod in the mandrel: a) scheme; b) full-scale specimen

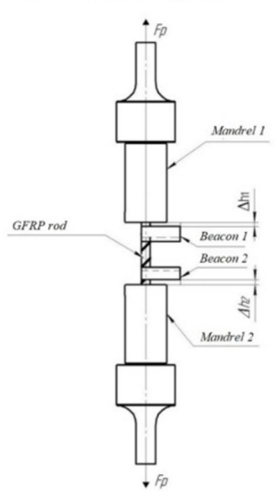

a)

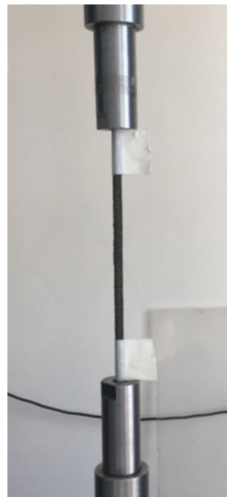

b)

Fig. 3. a) A testing configuration of devices used for tensioning the reinforcement; b) and fullscale view of the sample in gripping device

Pollack Periodica 15, 2020, 3 
After reaching a given force and holding for 60 seconds, the load was removed. The gaps $\Delta \mathrm{h} 1, \Delta \mathrm{h} 2$ were visually assessed and measured with a ruler when it was necessary.

In some cases, it was noted that the slippage of the rebar in the mandrel corresponded to an abrupt change in the tension force, which made it possible to determine the initial moment of slippage and the corresponding force Fss according to the loading diagram (Fig. 4, curve 2).

For each test, parameters regarding pre-fixing of the reinforcement and the tension characteristics were registered.

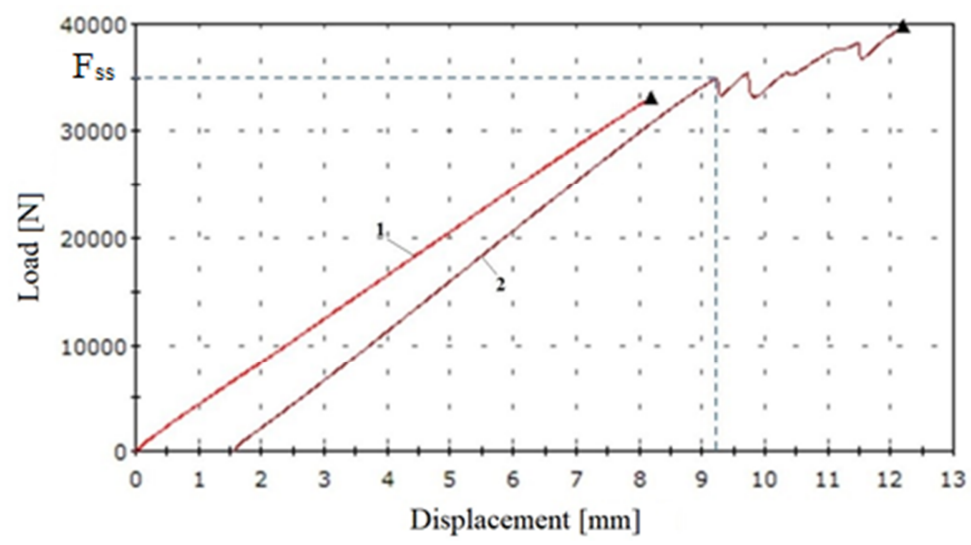

Fig. 4. Axial tension diagrams of rebar: 1 - without slippage; 2 - with slippage of the rod in the gripping device

\section{Analysis of test results}

Based on the method presented in the previous section, tests on different types of anchoring devices were carried out. Typical tension diagrams of reinforcement sample sets 1, 2 and 3 are presented in Fig. 5, respectively (the initial pressing force applied on anchor wedges was in the range of $41 \mathrm{kN}$ and $42 \mathrm{kN}$ ).

Diagrams show that the slippage of the ribbed reinforcing bars of set 1 is characterized by a sharp drop in the tension force (by 35-40\%) and a lower value of the initial sliding moment force. It can be explained by the specific characteristics of manufacturing and the weaker frictional properties of the tendons surface compared to other samples sets.

The test results of samples of reinforcement bars of set 1, set 2 and set 3 are presented in Fig. 6. They include obtained values of forces at the moment of initial sliding depending on the forces of preliminary pressing of anchor wedges and their trend line. Force $F$ corresponds to the minimum of forces F1 and F2 for each test.

Tests carried out on the device for tensioning the GFRP rods with anchor wedges with a length of $70 \mathrm{~mm}$ have shown that the maximum holding capacity is different when GFRP rods of a different profile are exposed to the short-term tensile load. 


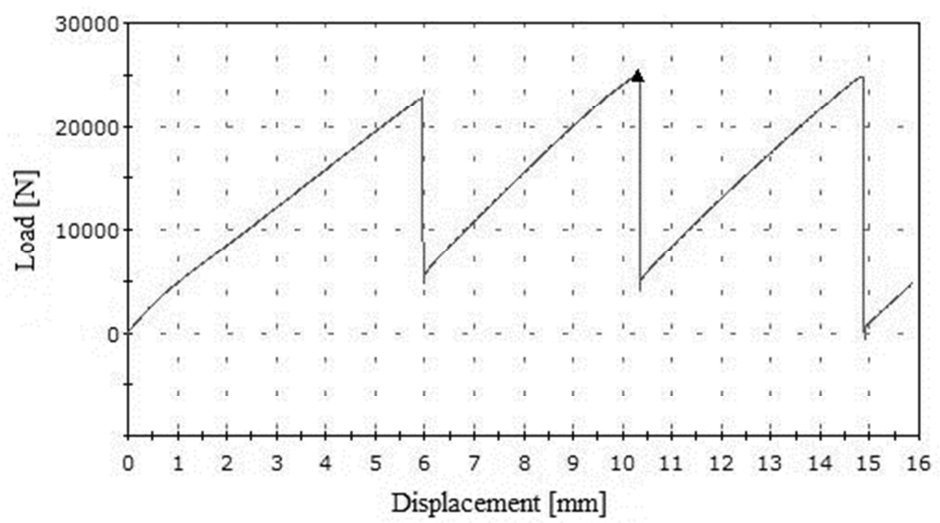

a)
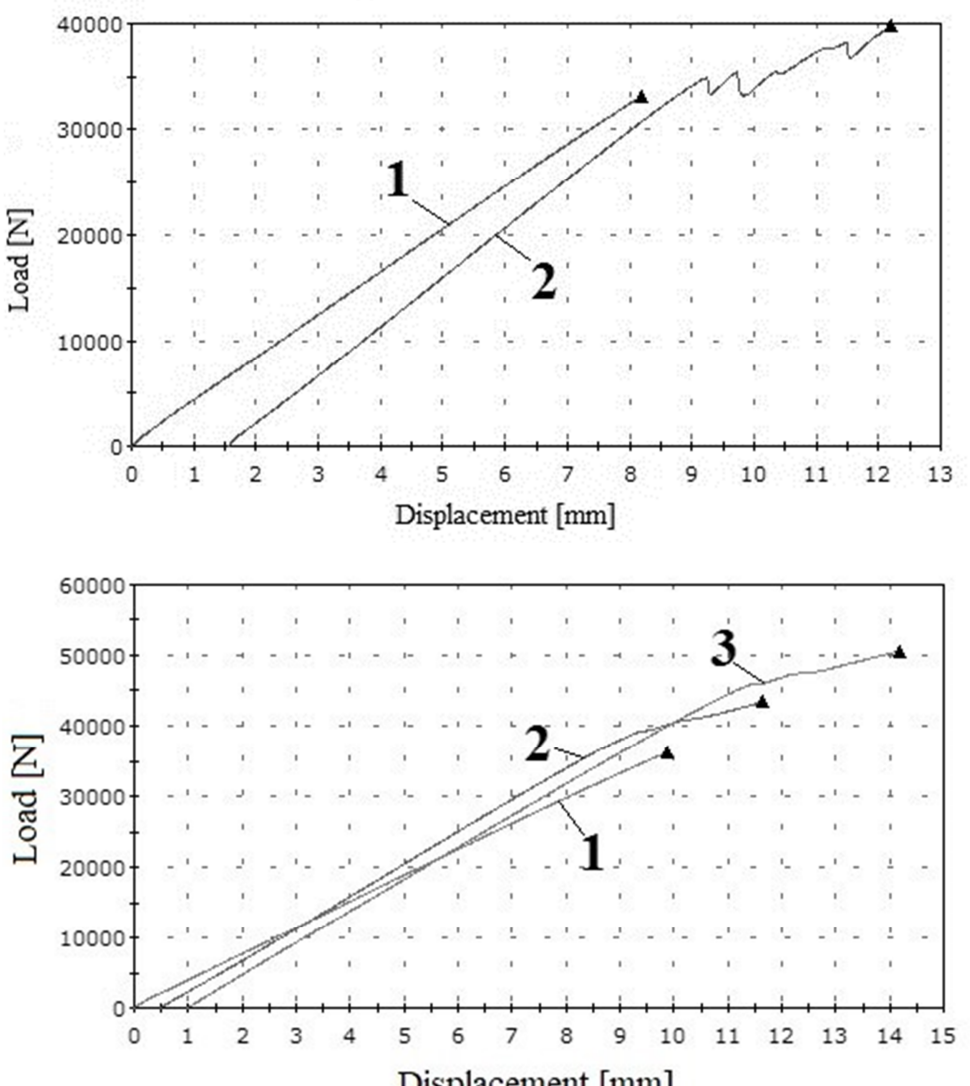

c)

Displacement [mm]

Fig. 5. Tendons tension diagrams: a) set 1; b) set 2; c) set 3

Pollack Periodica 15, 2020, 3 
The composite rod is fixed according to the regulatory requirements of $0.45 \sigma$ in accordance with SP 295.1325800.2017 'Concrete structures reinforced with polymer composite reinforcement design rules' by pre-fixing the ends of the rod and by providing compression of the polymer anchor wedges by pressing them depending on the type of FRP rod with forces as follows:

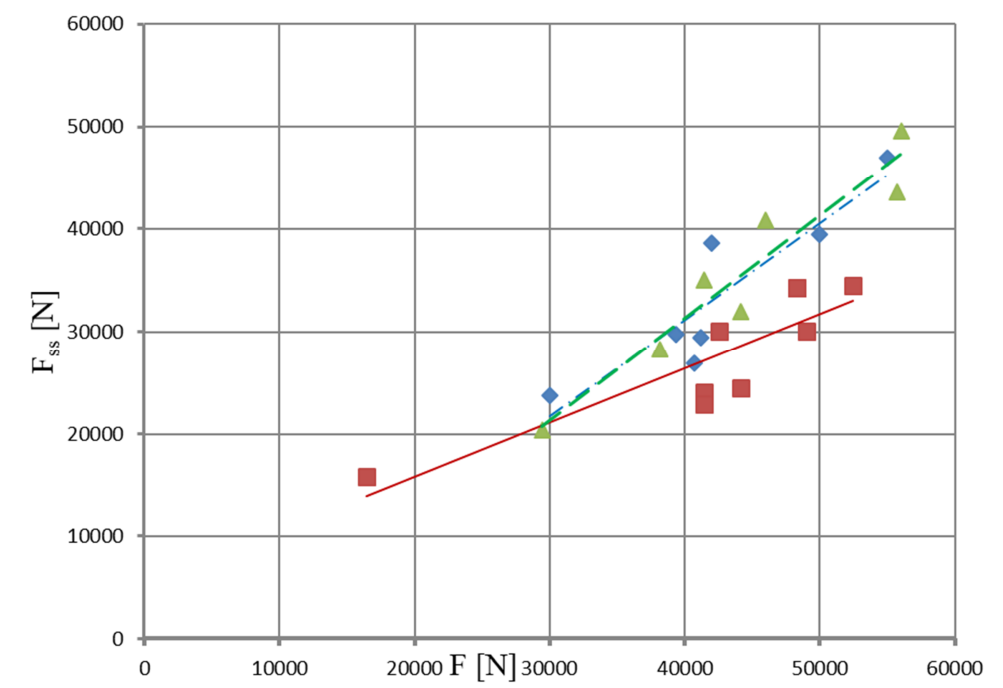

Fig. 6. Experimentally obtained values of force at the initial moment of sliding depending on the force of preliminary pressing of anchor wedges with a length of $1=70 \mathrm{~mm}$

( $\square$ - series $1, \nabla$ - series $2, \triangle$-series 3 )

for GFRP rods of set 1, the pressing force is $50 \mathrm{kN}$, which provides the force of the initial moment of slipping $F_{s s}=33.3 \mathrm{kN}$, or $48 \%$ of the ultimate load $F=70.32 \mathrm{kN}$

for GFRP rods of set 2, the pressing force is $40 \mathrm{kN}$, which provides the force of the initial moment of slipping $F_{s s}=31.2 \mathrm{kN}$, or $51 \%$ of the ultimate load $F=60.95 \mathrm{kN}$;

for GFRP rods of set 3, the pressing force is $55 \mathrm{kN}$, which provides the force of the initial moment of slipping $F_{s s}=46.6 \mathrm{kN}$, or $72 \%$ of the ultimate load $F=65.35 \mathrm{kN}$.

\section{Conclusions}

Results of experimental tests carried out on the developed device for placing and fixing reinforcing composite rebars and tendons have confirmed appropriate working capacity and successful avoidance of slippage during the tests in the required range of tension forces. 
It was noted that the material of anchor wedges, the strength and intensity of the preloading of fixing wedges, and the manufacturing technology of the reinforcing rebars have a significant effect on the performance of the gripping device.

It is concluded that for each diameter of the reinforcing rebar and type of profile to be tested, different parameter configurations are required to determine adequate fixing forces that enable the required tension of reinforcing tendons and tendons in prestressed concrete products.

For the developed gripping device recommended parameters of preliminary fixing of the reinforcing GFRP rods with a diameter of $8 \mathrm{~mm}$ and three different surface treatments were derived, ensuring their compliance with the regulatory requirements.

\section{Open Access statement}

This is an open-access article distributed under the terms of the Creative Commons Attribution 4.0 International License (https://creativecommons.org/licenses/by/4.0/), which permits unrestricted use, distribution, and reproduction in any medium, provided the original author and source are credited, a link to the CC License is provided, and changes - if any - are indicated. (SID_1)

\section{References}

[1] RU patent № 2008100546/22, Anchoring device for ribbed reinforcing bars, applicant and patent holder Ltd, 'Biysk fiberglass plant', (in Russian) 2008.

[2] RU patent № 2015127522/28, Sleeve for holding the rod of composite reinforcement, pulled out of concrete, applicant and patent holder FSEI of HE 'Ivanovo State Polytechnic University', (in Russian) 2016.

[3] RU patent № 2017110306, Connection element with a tip, applicant and patent holder V. N. Soplyachenko, O. G. Rogozhin, (in Russian) 2018.

[4] RU patent № 2016126915, Anchor device for fixing pre-stressed reinforcing bars, applicant and patent holder B.Sh. Umarov, 'Kazan State University of Architecture and Engineering', (in Russian) 2018.

[5] RU patent № 2016103166, Anchor for composite reinforcement element, applicant and patent holder V. N. Nikolaev, (in Russian) 2017.

[6] RU patent № 2016137575, Anchor for composite reinforcement element, V. N. Nikolaev, (in Russian) 2017.

[7] RU patent № 2016136420, Anchor for holding the power element made of composite material, applicant and patent holder: Institute of Applied Mechanics of the Russian Academy of Sciences, (in Russian) 2017.

[8] RU patent № 2015145714, Device for anchoring composite reinforcement: B. V. Nakashidze, P. B. Berezin, D. G. Nakashidze, (in Russian) 2017.

[9] BU patent № 20090077, Device for fastening the ends of fiberglass reinforcement, applicant and patent holder: Educational institution 'Polotsk State University', (in Russian) 2009.

[10] CN patent № 104727487A, Composite CFRP (Carbon Fibre Reinforced Polymer) tendon anchoring system, Han Qinghua, Wang Lichen, Xu Jie, Lu Yan, Xu Ying, 2015.

[11] US patent № 4958961, Anchoring arrangement for a rodshaped tension member formed of fiber reinforced composite material, Thomas Herbst, Dieter Jungwirt, 1990. 
[12] US patent № 5437526A, Arrangement for anchoring a rod-shaped tension member of composite fiber material, Thomas Herbst, Berthold Bolmer, Hartmut von Grolman, Anton Liigering, Lorenz Schnitzler, 1995.

[13] US patent № 5713169A, Anchorage device for high performance fiber composite cables, Urs Meier, Heinz Meier, Patrick Ki, 1998.

[14] Orban Z. Temporary strengthening of steel bridge element with FRP sheet, Pollack Periodica, Vol. 9, No. 2, 2014, pp. 35-44.

[15] Krasniqi C., Kabashi N., Krasniqi E., Kaqi V. Comparison of the behavior of GFRP reinforced concrete beams with conventional steel bars, Pollack Periodica, Vol. 13, No. 3, 2018, pp. 141-150.

[16] GOST 31938-2012, Fiber-reinforced polymer bar for concrete reinforcement, General specifications, adopted 01-01-2014, M. Standardinform, 2001.

[17] BU Patent № 20130021, Device for fastening the ends of fiberglass reinforcement, applicant and patent holder Educational institution 'Polotsk State University', 2013.

[18] Lobanov D. S. Experimental studies of the deformation and strength properties of polymer composite materials and filler panels, (in Russian) Thesis for Candidate Degree in Sciences, Perm National Research Politechnical University, 2015.

[19] Gizdatullin A. R., Khozin V. G., Kuklin A. N., Khusnutdinov A. M. Features of testing and the nature of the destruction of polymer composite reinforcement, (in Russian) Engineering Journal, No. 3, 2014, pp. 40-47.

[20] Stepanova V. F., Stepanov A. Yu., Zhirkov E. P. Composite polymer reinforcement, Moscow, ASV, 2013.

[21] Anchor wedges, (in German) http://www.paul.eu/ru/produkte/spannbeton-technik/ spannverankerungen.html (last visited 25 November 2019).

[22] Al-Mayah A., Soudki K., Plumtree A. Mechanical behavior of CFRP rod anchors under tensile loading, Journal of Composites for Construction, Vol. 5, No. 2, 2001, pp. 48-53.

[23] Bennitz A., Schmidt J. W. Täljsten B. Failure modes of prestressed CFRP rods in a wedge anchorage set-up, Proceedings of the 4th International Conference on Advanced Composites in Construction, Vol. 4, Edinburgh, United Kingdom, 1-3 September 2009, pp. 104-114.

[24] US Patent № 6082063, Prestressing anchorage system for fiber reinforced plastic tendons, Shrive N. G., 2000.

[25] ACI 440.4R, Prestressing concrete structures with FRP tendons, 2004.

[26] Al-Mayah A., Soudki K., Plumtree A. Effect of sandblasting on interfacial contact behavior of carbon-fiber-reinforced polymer-metal couples, Journal of Composites for Construction, Vol. 9, No. 4, 2005, pp. 29-43.

[27] Gar S. P. Structural performance of a full-depth precast bridge deck system prestressed and reinforced with AFRP bars, PhD Theis, Texas A\&M University, 2012.

[28] Al-Mayah A., Soudki K., Plumtree A. Novel anchor system for CFRP rod: Finite-element and mathematical models, Journal of Composites for Construction, Vol. 11, No. 5, 2007, pp. 355-359.

[29] RU Patent № 2011118956/03, Anchor device for composite reinforcement, applicant and patent holder LLC GALEN, (in Russian) 2011. 